\title{
Status of Geriatrics in 22 Countries
}

Pitkala, K. H.

2018-05

Pitkala , K H , Martin , F C , Maggi , S , Jyväkorpi , S K \& Strandberg , T E 2018 , ' Status of

Geriatrics in 22 Countries ' , Journal of nutrition, health \& aging , vol. 22 , no. 5 , pp. 627-631

. https://doi.org/10.1007/s12603-018-1023-7

http://hdl.handle.net/10138/302425

https://doi.org/10.1007/s12603-018-1023-7

publishedVersion

Downloaded from Helda, University of Helsinki institutional repository.

This is an electronic reprint of the original article.

This reprint may differ from the original in pagination and typographic detail.

Please cite the original version. 


\title{
STATUS OF GERIATRICS IN 22 COUNTRIES
}

\author{
K.H. PITKÄLÄ ${ }^{1}$, F.C. MARTIN ${ }^{2}$, S. MAGGI ${ }^{3}$, S.K. JYVÄKORPI ${ }^{1}$, T.E. STRANDBERG ${ }^{4,5}$
}

\begin{abstract}
1. University of Helsinki, Department of General Pratice and Primary Health Care and Helsinki University Hospital, Helsinki, Finland; 2. King's College London, London, United Kindom; 3. CNR Aging Program-IN, Padua, Italy; 4. University of Oulu, Center for Life Course Health Research, Oulu, Finland; 5. University of Helsinki, Clinicum, and Helsinki University Hospital, Helsinki, Finland. Corresponding author: Kaisu Pitkälä, Faculty of Medicine, Department of General Practice and Primary Health Care, PO BOX 20, 00014 University of Helsinki, Finland, email: kaisu.pitkala@helsinki.fi
\end{abstract}

\begin{abstract}
Objectives: The aim of this article is to describe the current status of geriatrics and position of geriatricians in 22 countries of three continents, and to portray their attitudes towards and resources allocated to geriatrics. Methods: An electronic survey was delivered to a convenience sample of 22 geriatricians in leading positions of their countries. Results: The time required in post graduation specialist training to become a geriatrician varied from one year (subspecialty in the USA) to six years (independent specialty in Belgium). The number in the population aged 80+ per geriatrician varied from 450 (Austria) to 25,000 (Turkey). Of respondents, $55 \%$ reported that geriatrics is not a popular specialty in their country. Acute geriatric wards, rehabilitation and outpatient clinics were the most common working places for geriatricians. Nearly half of the respondents had an opinion that older patients who were acutely ill, were receiving subacute rehabilitation or had dementia should be cared for by geriatricians whereas half of the respondents would place geriatricians also in charge of nursing home and orthogeriatric patients. The biggest problems affecting older people's clinical care in their countries were: lack of geriatric knowledge, lack of geriatricians, and attitudes towards older people. Half of respondents thought that older people's health promotion and comprehensive geriatric assessment were not well implemented in their countries, although a majority felt that they could promote good geriatric care in their present position as a geriatrician. Conclusion: The position of geriatric, geriatricians' training and contents of work has wide international variety.
\end{abstract}

Key words: Status of geriatrics, training, position of geriatricians, specialisation.

\section{Background}

Geriatrics deals with older people's health problems and rehabilitation, in the community, hospitals, subacute and longterm care settings and in their homes $(1,2)$. Key components of geriatric models are the management of chronic conditions, with a focus on functioning and well-being of older people according to patient preferences. Older people are very heterogeneous in respect to their health and functioning and, thus, their health and care needs differ considerably. Due to demographic change, the number of older patients with complex medical conditions is growing fast (3). Geriatrics may provide full range of services, but in some countries the focus of geriatrics is on specific aspects of care and specific settings.

The journey of development of geriatrics has varied considerably between different countries $(4,5)$, resulting in different contributions within the overall medical systems. There is no current comprehensive description of this range, so we rely mainly on descriptions from individual countries. In the U.K. geriatrics began in long-term care settings, and developed from the 1950s onwards in rehabilitation and post-acute care («traditional model of geriatrics»). Early pioneers struggled to establish its role distinct from the «younger sibling» of general internal medicine (GIM) into being recognized as its own specialty $(6,7)$. For example, geriatricians were responsible for patients chosen for them by other specialties, notably GIM (5, 6), but from the 1970s an «integrated model» evolved in which geriatricians looked after patients from the time of hospital admission alongside other specialists in shared wards. By the Received January 2, 2018 Accepted for publication January 3, 2018 end of the 20th century geriatrics had become the largest acute hospital specialty in the U.K. (8).

This hospital based pattern of development of geriatrics has been apparent in many other European countries in which it has become a specialty. In some countries geriatrics is located in smaller single specialty hospitals, which supports geriatrics as a specialty for subacute care. In a few countries, geriatrics developed, at least in part, in providing hospital based long-term care (5, 9-11). More recently, geriatrics has taken responsibility for nursing home medicine, although in some, this is in collaboration with primary care (France) (12) or as a distinct specialty of elderly care medicine, (initially nursing home physicians) separately from hospital geriatrics (13). In Finland and Canada, geriatrics has developed models within primary care in addition to hospital based roles (14).

In some European countries geriatrics is recognized as an independent medical specialty, but in others it is a subspecialty (10). In the U.S. geriatrics has remained a relatively small discipline in academic centers (7).

The aim of our article is to update and explore the current status of geriatrics and the position of geriatricians in 22 countries and three continents, including Europe, Australia/ New Zealand, and the U.S. We will also describe attitudes towards and resources allocated to geriatrics in those countries.

\section{Methods}

In 2014-2016 an electronic survey was delivered to a convenience sample of 22 geriatricians, selected because they Published online March 19, 2018, http://dx.doi.org/10.1007/s12603-018-1023-7 
Table 1

Items and their alternatives in the survey 2015-6

Question
How many geriatricians are there in your country?
How large is the population of $65+$ in your country?
How large is the population of $80+$ in your country?
(open; number)
What would be an adequate number of geriatricians in respondent's country?
How long is the training phase to become a geriatrician?
Is geriatrics its own specialty? Is it a subspecialty?
In what type of facilities do geriatricians usually work in your country? Place
them in order of commonness.

In what type of facilities should geriatricians work according to the respondent? Place them in order how you would prioritize them.

Who (what specialty) should take care of older patients?

- multimorbid geriatric patients

- acutely ill multimorbid patients

- older patients in rehabilitation

- stroke patients?

- hip fracture patients in rehabilitation?

-dementia patients?

- older people in community care?

What are the most important problems in older people's care in your country? Place them in order - number 1 the most problematic etc.

How is the prevention and health promotion implemented in older people's care in your country?

How is comprehensive geriatric assessment implemented in older people's care in your country?

Are you able to promote good geriatric care in your present work?

How is geriatricians' work generally appreciated?

How popular is geriatrics as a specialization in your country?

had leading positions in Geriatric Medicine in their countries (European countries, Australia, New Zealand, and the U.S.). The survey included several questions about the specialty of geriatrics, the duration of training to become a geriatrician, public appreciation of geriatricians' work, respondents' opinions about popularity of the specialty, problems in older people's care, the implementation (or not) of health prevention and health promotion in older people's care and to what extent they judged that comprehensive geriatric assessment

\section{Alternatives}

(open; number)

(open; number)

(open; number)

(in years and months)

Yes/no

acute geriatric wards/ subacute(rehabilitation) wards/ emergency department/ geriatric outpatient clinic/ orthogeriatric wards/ memory disorder outpatient clinics/ nursing homes/ home care/ private practice/ community care/ administration/ university or research or education/ coordinating older people's care and services at community level/ other - what (three most common were considered in analyses)

(alternatives the same as in previous item)

geriatrician/general practitioner/ neurologist/other - what?
Polypharmacy/ deteriorating health of older people/ shortage of nursing home beds/ lack of timely rehabilitation/ lack of geriatric knowledge/ lack of geriatricians/ attitudes/ other what

very well/well/moderately/rather poorly/poorly

very well/well/moderately/rather poorly/poorly

very well/well/moderately/rather poorly/poorly

very well/well/moderately/rather weakly/weakly

Very popular/ moderately popular/ not very popular was applied in their countries. The questions and choices are presented in table 1. Of those items with an order, we took each respondent's first three preferences for the analyses.

\section{Results}

Altogether, 22 leading geriatricians answered the survey. In 11 countries (all in Europe), geriatrics is recognized as a medical specialty (Belgium, Denmark, Finland, France, 


\section{THE JOURNAL OF NUTRITION, HEALTH \& AGING@}

Ireland, Italy, Lithuania, Spain, Sweden, the Netherlands, the U.K.), in nine countries it is a subspecialty (Australia, Austria, Iceland, Germany, New Zealand, Norway, Switzerland, Turkey, USA) and in two countries (Greece, Portugal) geriatrics is not recognized as either. The time needed for specialization varies between three years (France) and six years (Belgium) where geriatrics is a full specialty but between one (USA) to three years (e.g. Austria) where it is a subspecialty. In addition to the time in geriatrics, countries may have varying times for postgraduate training prior to specialization.

The size of population $80+$ years per geriatrician varies, with a median of 1500 (Switzerland), with low numbers of 450 (Austria) and 820 (Iceland) rising to 5000 (Lithuania) and 25000 (Turkey). Most respondents thought that their country should double the number of geriatricians.

The most common place currently for geriatricians to be working was acute geriatric wards: respondents from 17/22 countries placed them as the first, second or third most common working place. Subacute care or rehabilitation wards were the second most common (9/22 placed them as the first, second or third), outpatient clinics third ( 8 respondents), followed by memory clinics and universities (4 respondents each). There was a wide range of additional work roles including in nursing homes, coordination of community care, in emergency departments, in orthogeriatric wards, and doing administration.

Most respondents thought that the highest priority for geriatricians was in acute geriatric wards (16 respondents suggested this as the first, second or third most important working place). Eleven judged that geriatricians should work in subacute care or rehabilitation settings and nine prioritized outpatient clinics. (i.e. in the top three). Five respondents would also place geriatricians at universities, emergency departments, and orthogeriatric wards. Finally, three considered community care coordination and memory clinics among the three highest priority working places for geriatricians. On the other hand, $91 \%$ thought that geriatricians should take care of acutely ill, multimorbid patients, $82 \%$ of older patients in subacute care and rehabilitation, $77 \%$ patients with dementia and half of respondents also nursing home patients. Nearly all (91\%) would have placed GPs in charge of community-dwelling older people without special problems.

Comprehensive geriatric assessment (CGA) was regarded by $59 \%$ and older people's health promotion by $55 \%$ as at least moderately implemented in their country. The three most important problems in older people's care according to the respondents were lack of geriatric knowledge (17/22 placing this as the first, second or third most important problem), attitudes towards older people's care (12/22) and lack of geriatricians (11/22). However, 95\% (21/22) of respondents thought that they could -- at least moderately -- promote good geriatric care in their present work as geriatricians.

While $82 \%$ considered that geriatricians were generally at least moderately appreciated by the public in their country, 55\% $(11 / 20)$ thought that geriatrics was not a popular specialty to practice among doctors in their country. This varied between countries since in Finland and Ireland geriatrics is a very popular among young doctors whereas, for example, in the U.S., Spain, Germany, France and Denmark it was not a popular specialty.

\section{Discussion}

The place of geriatrics within the overall scope of medical care varies greatly between countries and across continents. This survey covers the scope and some quality aspects of geriatrics as currently practiced, the status of geriatrics as a specialty within adult medicine, training time to become a geriatrician, plus the opinions of the respondents (geriatrician leaders) on what geriatrics should be doing.

The key findings on current geriatrics were that acute hospital wards were the most common place for geriatricians to practice, followed by a larger variety of additional or alternative roles. It is noteworthy however that in two countries with well developed geriatrics, France and Australia, acute hospital ward care was not among the two most popular working places for geriatricians. There was reasonable consistency among the respondents taken as a whole, between the frequency of other current roles and opinions on priorities although dementia care was perhaps considered a greater priority than reflected in current practice. It may be that respondents took into account the small number of geriatricians in most countries in deciding what they considered to be the priorities, and in general resources for older people's care varies between countries.

The length of geriatric training varied markedly, though was generally longer where geriatrics is a separate specialty, rather than subspecialty. Overall postgraduate training time also varied, for example in Spain it begins immediately after graduation although the training content includes considerable experience in GIM. In the UK, specialty training starts 4 years after graduation.

Although the number of geriatricians in proportion to the older population (aged 80+) varies enormously, and half of respondents considered lack of geriatricians to be among the top three problems affecting older peoples' care in their country, most respondents suggested a doubling of geriatric numbers, which, if it happened, would not of course alter this wide variation. In view of the lack of popularity of geriatrics in some counties, this aspiration may not be achievable in the short term. The demographic changes and the view that the work of geriatricians was generally acknowledged by the public, however, suggest that the health services and professions need to self critically address this negative perception of geriatrics as a career choice.

Comprehensive geriatric assessment (CGA) is a process that includes individualized, comprehensive assessment of patient's health, function and resources (15) leading to targeted intervention. It is an evidence-based approach to the care of older people in acute hospitals $(16,17)$ and community settings 
(18), associated with important benefits over non specialist approaches. The clinical areas considered the more important for geriatricians to work in are those in which CGA can be beneficial if fully implemented, particularly acute care and rehabilitation. It is however surprising that so large a proportion of respondents $(59 \%)$ considered it to at least moderately implemented in their country, bearing in mind the general scarcity of geriatricians and their limited scope of practice.

In summary therefore, these survey results indicate that geriatrics has developed unevenly in size, status and scope of practice. Leading geriatricians recognize the limitations in general but do not have a clear consensus on the required size or scope of geriatrics. There is a need to identify more explicitly the added health benefits of geriatricians and their associated multidisciplinary teams. Health service evaluations may help but context will also shape what are the priorities for development in each country and what is the feasible approach to achieving these developments. Significant considerations are likely to include: the relative roles of hospitals and community resources in the overall architecture of healthcare; the state of development of primary care; the financial model of insurance payments or reimbursements; attitudes to ageing and healthcare. For example, fundamental to the development of hospital based geriatrics in the UK was the closure of most old large poorly resourced hospitals with sparse facilities for acute medicine and replacement by large district general hospitals to which all acutely ill adults were admitted. This took decades but rapid change is possible. In 2008 Austria did not have geriatrics as a specialty (9) but there are now a large number of geriatricians $(11,19)$.

The strategy to develop geriatrics will also change over time. Some countries have so few geriatricians that the realistic view of the respondent, for example from Turkey, is to place them in academic positions to teach new geriatricians. For the same reason geriatricians cannot have a major role in providing primary medical care (7). In the USA there is an attempt to solve this problem by training primary care practitioners to screen for geriatric syndromes with the Rapid Geriatric Assessment (20).

Although most universities in USA teach geriatrics, and academic geriatricians there have contributed enormously to the body of knowledge about geriatrics, there are relatively low numbers of geriatricians in the country, and this is not increasing (20). In fact, at present the number of practicing geriatricians in the USA is just over $50 \%$ of what it was in 1988 when the first specialty board was held. In the USA both family practitioners and internists can become geriatricians. However, the decrease in fellowship training to 1 year has markedly decreased interest in geriatrics as a specialty and also decreased academic output from USA. In addition, palliative care has become increasingly popular getting many applicants who would have become geriatricians. Likewise although US based geriatricians have made important contributions to long-term care (21), and many academic centers link residency programs to nursing homes (22), there is no requirement for the mandatory position of medical director to be a geriatrician. Many nursing home physicians are certified by the American Medical Directors Association.

The opinions in the present survey are in line with a survey performed among Finnish geriatricians in 2013 (14). The Finnish survey also identified the biggest problems in geriatric care to be lack of geriatric knowledge and lack of geriatricians (23). In Finland, geriatricians were surveyed in 2002, 2010 and $2014(14,23,24)$.

\section{Conclusion}

The position of geriatrics, organization of older people's care and geriatricians' training and contents of work vary widely between countries. There is a widely perceived lack of geriatricians and geriatric knowledge which adversely affects the quality of older people's healthcare worldwide. There is a need to better clarify the relative benefits and priorities for addressing these vital issues for older people and their health services.

Disclosure of interests: The authors declare that they have no conflict of interest concerning this article.

\section{References}

1. Duursma S, Castleden M, Cherubini A, et al. Position statement on geriatric medicine and the provision of health care services to older people. J Nutr Health Aging 2004; 8:190-5.

2. American Geriatrics Society Core Writing Group of the Task Force on the Future Geriatric Medicine. Caring for older Americans: The future of geriatric medicine. J Am Geriatr Soc 2005;53:S245-S56.

3. Cruz-Jentoft A, Franco A, Sommer P, Baeyens JP, Jankowska E, Maggi A, et al Silver paper: the future of health promotion and preventive actions, basic research, and clinical aspects of age-related disease- a report of the European Summit on AgeRelated Disease. Aging Clin Exp Res 2009;21: 376-85.

4. Morley J. A brief history of geriatrics. J Gerontol Med Sci 2004;59A:1132-52.

5. Crome P. Geriatrics in Europe, in H.M. Fillitt, K. Rockwood, and K. Woodhouse (ed). Brocklehurst's Textbook of Geriatric Medicine and Gerontology (Seventh Edition) Philadelphia: Saunders Elsevier; 2010. pp. 997-1004.

6. Grimley Evans, J. Geriatric medicine: a brief history. BMJ 1997;315:1075-7.

7. Hogan DB. Geriatrics in North America, in H.M. Fillitt, K. Rockwood, and K Woodhouse (ed). Brocklehurst's Textbook of Geriatric Medicine and Gerontology (Seventh Edition). Philadelphia: Saunders Elsevier; 2010. pp. 1005-9.

8. Pitkala K, Gladman J, Connolly M. Models of health care for older people. In Michel JP, Beattie BL, Martin FC, Walston JD (Eds). Oxford textbook of geriatric medicine. Third edition. Oxford University Press. 2018 (in press)

9. Michel JP, Huber P, Cruz-Jentoft AJ. Europe-wide survey of teaching in geriatric medicine. J Am Geriatr Soc 2008;56:1536-42.

10. Kolb G, Anderen-Ranberg K, Cruz-Jentoft A, O’Neill D, Topinkova E, Michel JP. Geriatric care in Europe - the EUGMS Survey part 1: Belgium, Czech Republic, Denmark, Germany, Ireland, Spain, Switzerland, United Kingdom. Eur Geriatr Med 2011;2:290-5.

11. Ekdahl A, Fiorini A, MAggi S, Pils K, Michel JP, Kolb G. Geriatric care in Europe - the EUGMS survey part II: malta, Sweden and Austria. Eur Geriatr Med 2012;3:388 91.

12. Rolland Y, Mathieu C, Piau C, Cayla F, Bouget C, Vellas B, de Souto Barreto P. Improving the Quality of Care of Long-Stay Nursing Home Residents in France. J Am Geriatr Soc 2016;64:193-9.

13. Schols J,. Crebolder HF, van Weel C. Nursing and nursing home physician: The Dutch experience. J Am Med Dir Assoc 2004;5:207-12.

14. Löppönen M, Heinonen P, Jartti L, Halminen M, Rajala T, Viitanen M, Pitkala K, Strandberg TE. Geriatricians feel growing external appreciation of their work. Survey among Finnish geriatricians in 2013. Eur Ger Med 2015;6:570-2.

15. Bernabei R, Venturiero V, Tarsitani P, Gambassi G. The comprehensive geriatric assessment: when, where, how. Crit Rev Oncol Hematol 2000;33:45-56.

16. Baztán, J.J., Suárez-García, F.M., López-Arrieta, J., Rodríguez-Mañas, L., RodríguezArtalejo, F. (2009) Effectiveness of acute geriatric units on functional decline, living 


\section{THE JOURNAL OF NUTRITION, HEALTH \& AGING@}

at home, and case fatality among older patients admitted to hospital for acute medical disorders: meta-analysis. BMJ 2009;338:b50

17. Ellis, G., Whitehead, M.A,, Robinson, D., O’Neill, D., Langhorne, P. (2011) Comprehensive geriatric assessment for older adults admitted to hospital: metaanalysis of randomised controlled trials. BMJ;343:d6553

18. Stuck AE, Siu AL, Wieland GD, Adams J, Rubenstein LZ. Comprehensive geriatric assessment: a meta-analysis of controlled trials. Lancet 1993;342:1032-6.

19. Reiter R, Diraoui S, Van Den Noortgate N, Cruz-Jentoft A on behalf of EAMA. How to become a geriatrician in different European Countries. Eur Geriatr Med 2014;5:34751 .

20. Morley JE, Adams EV. Rapid Geriatric Assessment. JAMDA 2015;16:808-12

21. Pacala JT, Ouslander JG, Saliba D. Robert L. Kane, MD (1940-2017). J Am Geriatr Soc 2017;65:1656-8.
22. Libow LS. The first geriatric residency-fellowship in the United States. J Gerontol 2004;59A:1165-6.

23. Strandberg TE, Koistinen P, Antikainen R, Kynsilehto EA, Määttä K, NIemelä M, Seppänen ML, Viramo P, Pitkälä K, O'Neill D. Increased work-satisfaction amongst geriatricians in Finland - an encouragement for further development of the specialty? Survey among geriatricians in Finland in 2008. Eur Geriar Med 2010;1:73-6.

24. Pitkala K, Strandberg T, Hartikainen S. Geriatricians are satisfied with their work. Findings from 2001 survey (In Finnish). Suom Lääkäril 2002;45:4615-7. 